\title{
Demographics of Undergraduate Students in Game Degree Programs in the U.S. and UK
}

\author{
Monica M. McGill \\ Bradley University \\ Peoria, IL \\ (309) 677-4148 \\ mmcgill@bradley.edu
}

\author{
Amber Settle \\ DePaul University \\ Chicago, IL \\ (312) 362-5324 \\ asettle@cdm.depaul.edu
}

\author{
Adrienne Decker \\ Rochester Institute of Technology \\ Rochester, NY \\ (585) 475-4653 \\ adrienne.decker@rit.edu
}

\begin{abstract}
Over the last decade, there has been a growth in the video game industry and, at the same time, game degree programs at postsecondary institutions worldwide have grown in quantity and quality. Representation of gender and race in games and in the game industry workforce is an important issue. We explore this topic in our research, providing an overview of the demographics of undergraduate students in game degree programs in the United States and the United Kingdom. We include race, gender, ethnicity, political preferences, sexual orientation and more. Gender results indicate that males make up the significant majority in undergraduate game programs. Women are significantly more likely to think that the gaming industry, programs at the university, and project teams at the university are not as diverse as men think they are. Women are also significantly more likely to report that their programs would benefit from more diversity than men.
\end{abstract}

\section{Categories and Subject Descriptors}

K.3.2 (Computer and Information System Education), K.8.0 (General)

\section{Keywords}

Games, demographics, undergraduate students, gender, diversity, curriculum

\section{INTRODUCTION}

Over the last decade, there has been general agreement that a lack of diversity exists in the game industry workforce. The International Game Developers Association (IGDA) has conducted two industry surveys on the topic [12, 13]. Recent topics on industry sites such as Gamasutra have indicated that this topic is being taken even more seriously, with diversity and representation in games being considered one of the top 5 trends of the game industry in 2012 [10].

Student demographics have been gathered in multiple disciplines and for groups of students at universities in general, with one of the largest being the CIRP Freshman Survey [11]. Studying

Permission to make digital or hard copies of all or part of this work for personal or classroom use is granted without fee provided that copies are not made or distributed for profit or commercial advantage and that copies bear this notice and the full citation on the first page. Copyrights for components of this work owned by others than ACM must be honored. Abstracting with credit is permitted. To copy otherwise, or republish, to post on servers or to redistribute to lists, requires prior specific permission and/or a fee. Request permissions from Permissions@acm.org.

SIGITE'13, October 10 - 12 2013, Orlando, FL, USA

Copyright 2013 ACM 978-1-4503-2239-3/13/10 ..\$15.00.

http://dx.doi.org/10.1145/2512276.2512278 student demographics is important for post-secondary institutions. For example, understanding what types of subjects students prefer in high school can provide insight into marketing strategies when recruiting so student interests and strengths are matched with prospective fields of study.

Individuals can break into the game industry in various ways, but all of these require the development of skills, knowledge, and dispositions that relate to the position being sought [2]. Game degree programs at post-secondary institutions have been created to provide a pathway to these skills. These programs have been on the rise worldwide and the number of programs recently hitting an all-time high [7]. They offer one potential pipeline into the game industry, and given the concern over the lack of diversity in the game industry workforce, it is natural to consider student demographics not only for issues related to diversity, but also whether students are properly matched for the field of study.

To date, no systematic studies of undergraduate game student demographics and perspectives on diversity exist. This paper presents the results of our study undertaken to begin this process. Specifically, our research considers the demographics of undergraduate students studying games at universities in the UK and US as well as their general attitudes about diversity in the game industry. We describe the study methodology, present the data collected on diversity within programs in both the US and $\mathrm{UK}$, and briefly explore what the results mean for the game industry.

\section{BACKGROUND}

While there has been some research into the study of demographics in the game industry, there is little previous work on demographics among undergraduate game students. We provide some insight into the relevance of demographics studies here.

\subsection{Game Industry Workforce Demographics}

Members of the game industry have studied the workforce to determine the demographics of employees within the industry and have recognized that diversity is important in the field. The IGDA implemented its second survey on diversity in the industry to establish a benchmark on issues of diversity in November 2011 [13]. This survey was a follow up to results of a 2005 survey that showed that the typical game development professional is "white, male, heterosexual, not disabled, [...] and agrees that workforce diversity is important to the future success of the game industry" [12, pp. 9-10].

Because the 2005 IDGA survey was crucial in the development of our study, it is worth considering it in more detail. Due to low response rates elsewhere, only responses from those living in the USA, Canada, the UK, and Australia were considered, giving a sample size of 3,128 . Of the responses $66 \%$ were from the U.S., 
$18 \%$ from Canada, $12 \%$ from the UK, and 4\% from Australia. There was little ethnic diversity in the respondents, with $83.3 \%$ identifying as white, $7.5 \%$ as Asian, $2.5 \%$ as Hispanic/Latino, $2.0 \%$ as black, and $4.7 \%$ as other. The gender balance among respondents was overwhelmingly male, with only $11.5 \%$ of respondents identifying as female.

The 2005 survey also asked about sexual orientation, and $92 \%$ of respondents identified as heterosexual, with $2.7 \%$ identifying as lesbian/gay, $2.7 \%$ as bisexual, and $2.6 \%$ refusing to answer. Only $0.96 \%$ of respondents identified as transgender. Bisexuals, lesbians, and gays both think that the game industry currently lacks diversity and believe that diversity is important. When asked about disabilities, $87 \%$ reported that they did not have any. Of the remaining $13 \%$, the most commonly reported disabilities were mental and cognitive. Cognitive disabilities were reported by $30 \%$, mental disabilities by $31 \%$, sight $9 \%$, hearing $6 \%$, mobility $4 \%$, other $11 \%$, and $9 \%$ declined to specify.

Women who responded to the 2005 survey strongly believed that diversity was important for the future of the industry and that diversity impacts the games that are produced. Interestingly, the study found that "non-whites seem to believe strongly that the industry is diverse and teams are diverse more often than whites". Overall, the IGDA concludes by recognizing the importance of diversity in the field both for a broader base of recruiting talent to the industry as well as the ability to create products to appeal to larger audiences.

\subsection{Demographics in Games}

There have been several important studies on gender and race representations in games and the impact this has on players. After analyzing representation of women in 33 games, Dietz [4] concluded that women in games were hypersexualized in graphical representation, and often had insignificant or stereotypical roles. A more recent study by Downs and Smith [5] concluded that women are still hypersexualized in games more so than men, which is consistent with other research performed on this topic $[14,16]$.

Other research has examined video games in context to race and offer consistent evidence of the lack of people of color and the reinforcement of racial stereotypes [9, 17, 18]. Leonard [15] goes as far as stating that video games such as the "racist racial project" Grand Theft Auto III "...reveal white supremacy in the form of both content and desire." (p. 6), also noting that racialized images in video games affirm our society's dominant ideas about various subgroups and these are framed through the lens of the dominant group producing such games.

Not only are demographics an issue, but also girls appear to be aware of this imbalance. Schott and Horrell noted in their study that not only were their study participants (all girls) aware of sexism in games, they "...claimed to desire a more balanced portrayal of males and females in games, as well as greater flexibility in character choice." [19, p. 50] They also conclude that several factors influence the amount of time girls play games, including the presence and dominance of male gamers.

The research by Williams, et al shows a correlation between the game industry workforce and the representation of race in games [21]. This is further supported by Everett and Watkins [8], both media critics, who believe that there should be "...broader debates about the rise and diffusion of digital media technologies and the educational pathways" for success in these domains, particularly as they pertain to race and ethnicity. They state that "... if high degrees of learning and education are essential for gaining meaningful employment in the video game industry, the future prospects of black and Latino talent finding a secure place among programmers, design artists, writers, and designers are limited." (p. 160)

\subsection{Previous Study of Game Students}

To date, the demographics and motivations of game students have been studied far less systematically and thoroughly. Bayliss and Bierre [1] performed a study comparing their game students to the student in other computing degree programs. They found that $10 \%$ of the students in their program were females and $90 \%$ male. They found that $25 \%$ of them want to focus on design and become game designers rather than game software developers. Many of them $(31 \%)$ had no prior programming experience before coming into the program. With regards to motivation for study, they found that $35 \%$ chose their major because they liked to program, with $2 \%$ choosing it because they liked problem solving, and $27 \%$ because they liked to express their creativity. One of their conclusions was that students who chose to pursue games as a major were more interested in expressing their creativity than their computing peers in other majors.

At University of California Santa Cruz, a large undergraduate course in games was offered to all students at the university that could have counted towards general education credit in the natural sciences area. Since all students need to complete a course in this area to graduate, the course was uniquely positioned to attract from all parts of the student body. The course did succeed in attracting more students from non-engineering majors; however, it still attracted a much larger proportion of males than females, affirming the trends that already exist in technical and engineering courses [20].

\section{METHODOLOGY}

To explore the research questions, we created the Game Industry Employee Pipeline Survey. Many of these questions were taken directly from the 2005 IGDA survey "Game Developer Demographics: An Exploration of Workforce Diversity" and the 2011 IGDA Industry Survey with permission. The survey consisted of nine demographic questions, one question about favorite high school subjects, four questions about religious preferences, sexual preferences, and political views, and two questions about disabilities (see the appendix for the survey questions). In addition, the survey elicited information about student perceptions of diversity in the game industry. This particular analysis examines the demographics of respondents from the US and the UK against results of the 2005 IGDA survey.

The initial population for this cross-sectional study included undergraduate students in game degree programs in the U.S., UK, and Canada. The institutions initially contacted included public, not-for-profit private, and for-profit private institutions that offered undergraduate degrees in games and included institutions of various sizes and locations with the specific intention of having data from students at a variety of institutions. Faculty at postsecondary institutions in the U.S., UK, and Canada were contacted to participate in the study and act as conduits for disseminating the study to their students. Due to this, faculty were required to receive Institutional Review Board/ethics committee approval at their respective institutions.

As a result, faculty at four institutions in the U.S., two institutions in the UK, and one institution in Canada completed this step. Upon their IRB approval, the surveys were distributed to students within participating institutions between March 1, 2012 and 
September 20, 2012. Not enough responses were received from students in Canada to include in the summary. Of the four institutions in the US, three were private institutions and one was public. Both of the institutions in the UK were public institutions.

Two emails were sent to participants on behalf of the faculty researcher, the first announcing the survey and inviting participation. A survey reminder was sent one week after the first. In Canada, the local researcher solicited student participation.

The data collection followed techniques that were previously approved by the researcher's committees on research of human subjects. To gather the data, an electronic form of the survey instrument was created using the Qualtrics online survey tool. Only participants who agreed to the letter of consent that appeared on the first page of the survey were able to complete the survey. As an incentive, participants in the UK and U.S. were offered a chance to enter a prize drawing for a tablet computer upon completion of the survey. To enter the drawing, participants followed a link to a second survey in order to keep the demographic data for the survey separate from the drawing survey that required participants to enter the contact information. Upon completion of data collection, the drawing was held and the prize was awarded. The data from the drawing survey was then destroyed.

Once the data was collected, it was analyzed with the SPSS software tool. Descriptive statistics, specifically frequency counts and percentages were used to answer the questions pertaining to the demographics of students in game degree programs. T-tests were performed on male versus female and white versus nonwhite responses to understand statistically significant differences in these populations. To ensure internal consistency among the diversity perspectives questions, a Cronbach's Alpha test was performed.

\section{RESULTS}

There were a total of 315 responses to the surveys from U.S. and UK institutions from the 1240 students emailed. With only one response from Canada, the response was removed from data analysis. Of the U.S. and UK respondents, two were not undergraduates and were eliminated from the data set, bringing the total to 313 , a $25.2 \%$ response rate. In this section we first present student demographics for the 313 undergraduate respondents, including general demographic data (including age, sex, ethnicity), areas of study within games and career interests, religious and political leanings, sexual orientation, and medically diagnosed disabilities. Following this we present a general summary of perceptions of diversity, and then discuss differences between responses for male versus female and white versus nonwhite participants.

\subsection{Demographic Data}

Nearly all respondents were fulltime undergraduate students (98.1\%) with the remaining students attending part-time. Participants from each year of study responded, though it should be noted that the US system requires four years of study and UK programs often only require three. $94.9 \%$ of participants were in the $18-24$ age range, $4.5 \%$ in the $25-30$ range, and $0.6 \%$ in the $31-$ 50 range.

The majority of students $(96.8 \%)$ were enrolled in a Bachelors Degree in games (i.e. Game Design, Game Development, Game Art, etc.). Only $2.9 \%$ indicated that they were enrolled in a Bachelors Degree in a related field, with a concentration in games.
A majority of students studying games are male (87.2\%) compared to female $(12.8 \%)$. The respondents were primarily native English speakers (92.0\%) and white (73.5\%). Other ethnicities are reported in Table 1.

TABLE I. ETHNICITY

\begin{tabular}{|l|r|r|}
\hline \multicolumn{1}{|c|}{ Categories } & Count & \multicolumn{1}{c|}{$\%$} \\
\hline White & 227 & $72.3 \%$ \\
\hline Black & 19 & $6.1 \%$ \\
\hline Chinese & 10 & $3.2 \%$ \\
\hline Hispanic/Latino & 7 & $2.2 \%$ \\
\hline South Asian (eg East Indian, Sri Lankan, etc.) & 5 & $1.6 \%$ \\
\hline Filipino & 4 & $1.3 \%$ \\
\hline Southeast Asian (eg., Vietnamese, Camobidan) & 4 & $1.3 \%$ \\
\hline Japanese & 3 & $1.0 \%$ \\
\hline Korean & 3 & $1.0 \%$ \\
\hline West Asian (e.g., Iranian, Afghan, etc.) & 2 & $0.6 \%$ \\
\hline Arab & 1 & $0.3 \%$ \\
\hline Other & 11 & $3.5 \%$ \\
\hline Decline to Answer & 13 & $4.1 \%$ \\
\hline
\end{tabular}

\subsubsection{Areas of Study and Career Interests}

All 313 participants responded to questions in the survey identifying each student's area of study within games. Participants could choose multiple areas of study. Fourteen participants selected "other". Respondents indicating "other" who also selected a listed area were classified according to that area, and respondents who did not select another area were counted in the area closest to the text provided, with game culture counting as game design. The respondent who selected everything was added to each of the other categories.

TABLE II. AREAS OF STUDY

\begin{tabular}{|l|r|r|}
\hline \multicolumn{1}{|c|}{ Areas of Study } & Count & \multicolumn{1}{c|}{$\%$} \\
\hline Game Design & 265 & $84.7 \%$ \\
\hline Game Software Development & 198 & $63.3 \%$ \\
\hline Game Production & 117 & $37.4 \%$ \\
\hline Game Art & 68 & $21.7 \%$ \\
\hline Game Sound & 27 & $8.6 \%$ \\
\hline Undecided & 2 & $0.6 \%$ \\
\hline
\end{tabular}

For interest in careers in games, all 313 participants responded. Only one career interest could be selected. Several participants $(12.1 \%)$ stated that they were undecided, while 4 participants $(1.3 \%)$ indicated that they do not intend to pursue a career in the game industry. Twenty-four participants selected "other" and each provided text to describe their interests. They were classified in the listed area that best matched their text response. 
TABLE III. CAREER INTERESTS

\begin{tabular}{|l|r|r|}
\hline \multicolumn{1}{|c|}{ Career Interests } & Count & \% \\
\hline $\begin{array}{l}\text { Software Development (Programming, Software } \\
\text { Analysis, Software Engineering, etc.) }\end{array}$ & 126 & $40.2 \%$ \\
\hline Level Designer & 43 & $13.7 \%$ \\
\hline Undecided & 38 & $12.1 \%$ \\
\hline Artist & 36 & $11.5 \%$ \\
\hline Producer & 25 & $8.0 \%$ \\
\hline Design & 10 & $3.2 \%$ \\
\hline Administrative & 7 & $2.2 \%$ \\
\hline Writer & 6 & $2.0 \%$ \\
\hline Business Management & 5 & $1.6 \%$ \\
\hline Testing & 5 & $1.6 \%$ \\
\hline $\begin{array}{l}\text { I do not indent to pursue a career in the game } \\
\text { industry }\end{array}$ & 4 & $1.3 \%$ \\
\hline Quality Assurance & 3 & $1.0 \%$ \\
\hline Audio & 3 & $1.0 \%$ \\
\hline Consultant & 1 & $0.3 \%$ \\
\hline Marketing/PR & $0.3 \%$ \\
\hline
\end{tabular}

\subsubsection{Favorite High School Subject}

Participants were asked to identify their favorite subject in high school. Only one subject could be chosen, and there were only 309 responses to this question which was the value used to compute the percentages in the table below. As might be expected, the most popular favorite subjects include technology courses, art, and mathematics. The full set of responses for the favorite subjects is provided in the table below.

TABLE IV. FAVORITE HIGH SCHOOL SUBJECT

\begin{tabular}{|l|r|r|}
\hline \multicolumn{1}{|c|}{ Subject } & \multicolumn{1}{c|}{ \# } & \% \\
\hline $\begin{array}{l}\text { Technology courses (computer science, } \\
\text { multimedia) }\end{array}$ & 85 & $27.5 \%$ \\
\hline Art (drawing, sculpting, graphic design, etc.) & 60 & $19.4 \%$ \\
\hline Mathematics & 56 & $18.1 \%$ \\
\hline Social Studies (civics, history, geography, etc.) & 24 & $7.8 \%$ \\
\hline Physics & 20 & $6.5 \%$ \\
\hline English & 19 & $6.2 \%$ \\
\hline Music (orchestra, band, choir) & 17 & $5.5 \%$ \\
\hline Science (chemistry, biology) & 10 & $3.2 \%$ \\
\hline Foreign language & 8 & $2.6 \%$ \\
\hline Other & 6 & $1.9 \%$ \\
\hline Engineering & 4 & $1.3 \%$ \\
\hline
\end{tabular}

\subsubsection{Religious and Political Leanings}

A total of 306 participants responded to the religious preferences question, with $34(11.1 \%)$ declining to specify their religion (Table V). The majority $(44.9 \%)$ of participants did not have a religious preference. $12.1 \%$ identified as Roman Catholic while 9.5\% identified as Other Christian.

For political preferences, 306 participants responded, with most identifying as not caring about politics $(28.4 \%)$ or being liberal $(25.5 \%)$. Another large percentage $(21.2 \%)$ identified with middle-of-the-road ideologies. $8.5 \%$ specified other and $7.5 \%$ declined to specify. Among those who selected other, 7 (2.3\%) specified Libertarian beliefs, $7(2.3 \%)$ indicated that it depended on the issue, and $1(0.3 \%)$ each indicated Democrat and Labour.

The remaining respondents provided colorful commentary, noting among other things that "rent is too damn high", that "our political system is a circus of idiocy run by sadistic clowns", that they identified with "whoever is not saying crazy things" or those who support "gun rights", that they "disagree with the entire system" or that "all of them are thieves."

TABLE V. RELIGIOUS PREFERENCE

\begin{tabular}{|l|r|r|}
\hline \multicolumn{1}{|c|}{ Preference } & Count & \multicolumn{1}{c|}{$\%$} \\
\hline None & 141 & $46.1 \%$ \\
\hline Roman Catholic & 37 & $12.1 \%$ \\
\hline Decline to specify & 34 & $11.1 \%$ \\
\hline Other Christian & 29 & $9.5 \%$ \\
\hline Other Religion & 12 & $3.9 \%$ \\
\hline Baptist & 10 & $3.3 \%$ \\
\hline Church of Christ & 9 & $2.9 \%$ \\
\hline Muslim & 7 & $2.3 \%$ \\
\hline Jewish & 6 & $2.0 \%$ \\
\hline Methodist & 5 & $1.6 \%$ \\
\hline Presbyterian & 4 & $1.3 \%$ \\
\hline Lutheran & 4 & $1.3 \%$ \\
\hline Episcopaleon & 3 & $1.0 \%$ \\
\hline Eastern Orthodox & 2 & $0.7 \%$ \\
\hline Buddhist & 1 & $0.7 \%$ \\
\hline Hindu & & $2 \%$ \\
\hline
\end{tabular}

TABLE VI. POLITICAL PREFERENCES

\begin{tabular}{|l|r|r|}
\hline \multicolumn{1}{|c|}{ Preference } & Count & \multicolumn{1}{c|}{$\%$} \\
\hline Don't care & 87 & $28.4 \%$ \\
\hline Liberal & 78 & $25.5 \%$ \\
\hline Middle of the road & 65 & $21.2 \%$ \\
\hline Other & 26 & $8.5 \%$ \\
\hline Decline to specify & 23 & $7.5 \%$ \\
\hline Conservative & 19 & $6.2 \%$ \\
\hline Far left & 6 & $2.0 \%$ \\
\hline Far right & 2 & $0.7 \%$ \\
\hline
\end{tabular}

\subsubsection{Sexual Orientation}

A total of 305 participants responded to the question about sexual orientation, with the majority reporting that they are heterosexual (262 or $83.4 \%)$. $21(6.7 \%)$ reported being bisexual, $18(5.7 \%)$ declined to specify, and $4(1.3 \%)$ reported being lesbian or gay, as shown in Table VII. 
TABLE VII. SEXUAL ORIENTATION

\begin{tabular}{|l|r|c|}
\hline \multicolumn{1}{|c|}{ Orientation } & Count & \multicolumn{1}{c|}{$\%$} \\
\hline Heterosexual & 262 & $83.4 \%$ \\
\hline Bisexual & 21 & $6.7 \%$ \\
\hline Decline to specify & 18 & $5.7 \%$ \\
\hline Lesbian/gay & 4 & $1.3 \%$ \\
\hline
\end{tabular}

A total of 304 respondents responded to the question asking whether they were transgender, with 297 (97.7\%) reporting no, 5 $(1.6 \%)$ declining to specify, and $2(0.7 \%)$ reporting yes (Table VIII).

TABLE VIII. TRANSGENDER STATUS

\begin{tabular}{|l|r|r|}
\hline \multicolumn{1}{|c|}{ Status } & Count & \multicolumn{1}{c|}{$\%$} \\
\hline No & 297 & $97.7 \%$ \\
\hline Decline to specify & 5 & $1.6 \%$ \\
\hline Yes & 2 & $0.7 \%$ \\
\hline
\end{tabular}

\subsubsection{Disabilities}

Participants were asked to identify one or more medically diagnosed disabilities. The majority $(67.5 \%)$ of participants stated that they did not have a disability (Table IX). The remaining responses are summarized below with the $5(1.6 \%)$ indicating another disability, reporting dyslexia, diverticulitis, lazy eye, hemophilia, and color blindness.

TABLE IX. DISABILITIES

\begin{tabular}{|l|r|c|}
\hline \multicolumn{1}{|c|}{ Disability Count } & $\%$ \\
\hline None & 212 & $67.5 \%$ \\
\hline $\begin{array}{l}\text { Mental illness (e.g. anxiety, obsessive } \\
\text { compulsive disorder, post-traumatic stress } \\
\text { disorder, bipolar, depressions, schizophrenia, } \\
\text { etc.) }\end{array}$ & 28 & $8.9 \%$ \\
\hline $\begin{array}{l}\text { Cognitive disorder (e.g. dyslexia, ADD/HD, } \\
\text { specific learning disability, autism, Asperger's, } \\
\text { etc.) }\end{array}$ & 26 & $8.3 \%$ \\
\hline Blind or partially sighted & 9 & $2.9 \%$ \\
\hline Decline to answer & 8 & $2.5 \%$ \\
\hline Yes, decline to specify paraplegia, & 5 & $1.6 \%$ \\
\hline Other & 1 & $1.6 \%$ \\
\hline Deaf or hard of hearing & 3 & $1.0 \%$ \\
\hline $\begin{array}{l}\text { Mobility impaired (e.g. } \\
\text { quadraplegia, cerebral palsy, ALS, etc.) }\end{array}$ & $0.3 \%$ \\
\hline
\end{tabular}

A second question was posed to respondents who indicated that they had a cognitive disability (Table $\mathrm{X}$ ). Of these, ADD/HD was the most common following by dyslexia and Asperger's.

The one respondent who specified "other" under disabilities but reported dyslexia was added to the total for that specific learning disability. One respondent answered "other" to the question about cognitive disorders, specifying OCD for Obsessive Compulsive Disorder. This response was classified under mental illness in the table above and not counted here.

\section{TABLE X. Cognitive DisABILITIES}

\begin{tabular}{|l|r|r|}
\hline \multicolumn{1}{|c|}{ Disability } & \multicolumn{1}{c|}{ Count } & \multicolumn{1}{c|}{$\%$} \\
\hline ADD/HD & 16 & $5.1 \%$ \\
\hline Dyslexia & 6 & $1.9 \%$ \\
\hline Asperger's & 5 & $1.6 \%$ \\
\hline Learning disability & 3 & $1.0 \%$ \\
\hline Austism & 1 & $0.3 \%$ \\
\hline
\end{tabular}

\subsection{Perceptions on Diversity}

The survey included several questions on issues related to diversity both in the game industry and the institution in which the participants were studying. These survey items were similar to items presented on the 2005 IGDA survey with the same Likert responses. Participants were asked to rate diversity-related questions on a Likert scale where $1=$ Strongly Disagree, $2=$ Disagree, 3 = Agree, and $4=$ Strongly Agree. Cronbach's alpha was performed on internal reliability and was deemed to be reliable $(\alpha=0.73)$.

In general students agreed that the game industry was diverse, that a diverse workforce has an impact on the games produced, and that workforce diversity is important to the future success of the game industry (Table XI). They agreed less strongly about diversity in their programs.

TABLE XI. DIVERSITY PERSPECTIVES

\begin{tabular}{|c|l|c|c|c|}
\hline Q & \multicolumn{1}{|c|}{ Diversity Statement } & N & M & SD \\
\hline 1 & The game industry workforce is diverse. & 306 & 3.06 & 0.751 \\
\hline 2 & My program at my university is diverse. & 306 & 2.96 & 0.730 \\
\hline 3 & $\begin{array}{l}\text { Project teams in my game degree } \\
\text { program are diverse. }\end{array}$ & 305 & 2.83 & 0.686 \\
\hline 4 & $\begin{array}{l}\text { In one or more of my courses, we have } \\
\text { discussed diversity. }\end{array}$ & 306 & 2.55 & 0.883 \\
\hline 5 & $\begin{array}{l}\text { A diverse workforce has a direct impact } \\
\text { (broad appeal, quality, etc.) on the } \\
\text { games produced. }\end{array}$ & 305 & 3.03 & 0.819 \\
\hline 6 & $\begin{array}{l}\text { My program would benefit from more } \\
\text { diverse students. }\end{array}$ & 305 & 2.90 & 0.766 \\
\hline 7 & $\begin{array}{l}\text { Workforce diversity is important to the } \\
\text { future success of the game industry. }\end{array}$ & 306 & 3.08 & 0.772 \\
\hline
\end{tabular}

We considered differences between populations regarding diversity. An independent-samples t-test was performed comparing male and female respondents. The responses for two of the questions were found to be significantly different $(\mathrm{p}<.05)$. Male respondents indicated higher agreement for "My program at my university is diverse," and female respondents indicated higher agreement for "My program would benefit from more diverse students." Table XII shows the results. 
TABLE XII. DIVERSITY PERSPECTIVES BY GENDER

\begin{tabular}{|c|c|c|c|c|c|c|c|c|}
\hline \multirow{2}{*}{ Q \# } & \multicolumn{3}{|c|}{ Female } & \multicolumn{3}{|c|}{ Male } & \multirow{2}{*}{ p } & \multirow{2}{*}{ t } \\
\cline { 2 - 7 } & $\mathbf{N}$ & $\mathbf{M}$ & SD & N & M & SD & & \\
\hline 1 & 40 & 2.65 & .66 & 266 & 3.12 & .75 & 0.00 & $\mathrm{t}(304)=-3.74$ \\
\hline 2 & 40 & 2.55 & .85 & 266 & 3.03 & .69 & 0.00 & $\mathrm{t}(304)=-3.94$ \\
\hline 3 & 40 & 2.53 & .64 & 265 & 2.88 & .68 & 0.00 & $\mathrm{t}(303)=-3.05$ \\
\hline 4 & 40 & 2.38 & .81 & 265 & 2.57 & .89 & 0.19 & $\mathrm{t}(304)=-1.31$ \\
\hline 5 & 39 & 2.90 & .88 & 266 & 3.05 & .81 & 0.27 & $\mathrm{t}(303)=-1.11$ \\
\hline 6 & 40 & 3.10 & .59 & 265 & 2.88 & .79 & 0.04 & $\mathrm{t}(303)=1.73$ \\
\hline 7 & 40 & 3.25 & .67 & 266 & 3.06 & .78 & 0.14 & $\mathrm{t}(304)=1.45$ \\
\hline
\end{tabular}

We performed an independent-samples t-test comparing white and non-white responses. There were no significant differences between the two groups on any of the questions. The information for each is presented in the table below.

TABLE XIII. DIVERSITY PERSPECTIVES BY ETHNICITY

\begin{tabular}{|c|c|c|c|c|c|c|c|c|}
\hline $\mathbf{Q}$ & \multicolumn{3}{|c|}{ White } & \multicolumn{3}{c|}{ Non-white } & \multirow{2}{*}{ p } & \multirow{2}{*}{ t } \\
\cline { 2 - 7 }$\#$ & $\mathbf{N}$ & M & SD & N & M & SD & & \\
\hline 1 & 224 & 3.08 & .73 & 69 & 3.00 & .82 & 0.41 & $\mathrm{t}(291)=0.82$ \\
\hline 2 & 224 & 2.97 & .71 & 69 & 2.90 & .83 & 0.46 & $\mathrm{t}(291)=0.74$ \\
\hline 3 & 224 & 2.85 & .67 & 69 & 2.74 & .78 & 0.24 & $\mathrm{t}(291)=1.18$ \\
\hline 4 & 224 & 2.53 & .89 & 69 & 2.59 & .91 & 0.61 & $\mathrm{t}(291)=-0.51$ \\
\hline 5 & 223 & 3.00 & .80 & 69 & 3.16 & .89 & 0.15 & $\mathrm{t}(290)=-1.45$ \\
\hline 6 & 223 & 2.83 & .77 & 69 & 3.12 & .74 & 0.00 & $\mathrm{t}(290)=-2.69$ \\
\hline 7 & 224 & 3.03 & .76 & 69 & 3.25 & .81 & 0.04 & $\mathrm{t}(291)=-2.02$ \\
\hline
\end{tabular}

\section{DISCUSSION}

This study provided important information about demographics and perceptions of diversity among game students in the U.S. and UK. Like a previous study of game students [1], our work found $87.2 \%$ of these students are male and that a large percentage $(84.7 \%)$ of students are studying game design. Like many other technology-focused fields, a large majority of students $(72.3 \%)$ are white, with Asians (10\%) as the second largest ethnic group. Similar to the IGDA study, our results found that a large majority of students $(83.4 \%)$ identify as heterosexual. Our work found a similar percentage of transgender game students $(0.7 \%)$ as found in the industry as a whole $(0.96 \%)$. Like the game industry as a whole, mental illness and cognitive disabilities are the most commonly reported disabilities.

Unlike a previous study of game students [1], our results show that many students $(63.3 \%)$ are studying software development with large percentages learning production $(37.4 \%)$ and game art (21.7\%). Again, contrary to previous work [1] only $16.9 \%$ of students plan to want to focus on game design after graduation. A much higher percentage $(40.2 \%)$ intends to focus on software development, and a reasonable percentage $(11.5 \%)$ intends to focus on art after graduation. Students who study games named technology classes (27.5\%), art (19.4\%), and mathematics $(18.1 \%)$ as their favorite high school subjects.

Many game students (46.1\%) do not identify with any religion, and among those who do identify with a religion Roman Catholics $(12.1 \%)$ and other Christians $(9.5 \%)$ are the most common. Game students are split on their political preferences with the largest group $(28.4 \%)$ indicating that they don't care about politics. Among those who specified a political preference, the majority
$(25.5 \%)$ is liberal or middle of the road $(21.2 \%)$. Conservatives are uncommon (6.2\%) among the respondents to this survey.

Our results show a larger percentage of bisexual students $(6.7 \%)$ and a lower percentage of lesbian/gay students (1.3\%) than found in the IGDA survey in 2005. Our work found a larger percentage of students with disabilities $(24.6 \%)$ than in the IGDA survey $(13 \%)$. We also provided detailed information about the specific cognitive disabilities among students, the most common of which was $\mathrm{ADD} / \mathrm{HD}$.

Students agreed that the game industry workforce is diverse, that a diverse workforce has a direct impact on the games produced, and that workforce diversity is important to the future success of the game industry. The agreement was less conclusive that the programs and project teams in academic are diverse, and it appeared that discussions of diversity were not uniform in game programs. Our results indicate that women are significantly more likely to think that the gaming industry workforce, programs at the university, and project teams at the university are not as diverse as men think they are. Women are also significantly more likely to report that their programs would benefit from more diversity than men.

\section{LIMITATIONS}

Even with this demographic study, both internal and external threats to its validity exist. The instrument was developed based on previous studies, including the IGDA Diversity study, and has not been validated. Participants from the six institutions may not be representative of the entire population of game students in the US and UK. Students in their first year of studies had a higher participation rate than for each of the other years of study, and this may influence the outcomes of the study as well, since first-year students are more likely to change majors than students in their later years of study.

Some of the questions posed are sensitive in nature. Participants may or may not choose to respond to these truthfully or may have chosen the "Decline to Answer" or "Decline to Specify" choice available on several of the required response questions. The entire study is based on self-reports provided by participants, and care must be taken when interpreting the results. Additionally, though care was taken in choosing survey questions and choices that are unambiguous, there is a risk that the participant may have misinterpreted the questions or choices.

\section{CONCLUSION}

Though this paper examined the role of diversity perceptions with an emphasis on gender and race, continuation of this research and data analysis is ongoing. Additional planned analysis includes how the data compares specifically to the results of both IGDA surveys as well as the general population and how marginalized groups like black women and persons with disabilities compare to in-game characterizations.

This study answers the question of what types of students study games, while at the same time raises the question about what this data implies. If the game industry believes that workforce diversity is important and their goal is to make their workforce more diverse, then some of the demographics should raise serious concerns. For example, one of the most glaring results of this research is the gender imbalance. For those that are concerned with this issue as either a moral imperative or as a pathway for potentially reaching more consumers, this issue should be examined more closely and in context of industry goals. As noted 
by Everett and Watkins [8], if the industry is serious about making changes, then the university pipeline may be a potentially powerful place to start addressing the imbalances and providing better opportunities for minorities. In other technology-focused disciplines, much of the focus on recruitment has extended back into secondary and middle school [3], with the recognition that many students have made up their mind about their choice of major prior to entering college or university. It may be benefit for those who are interested in diversifying the gaming industry to consider a similar approach.

\section{ACKNOWLEDGEMENTS}

We would like to thank the following people for their time and resources in shepherding the IRB process at their respective institutions and recruiting students for participation: Briana Morrison, Southern Polytechnic State University; Jacques Carette, McMaster University; Mark Eyles, University of Portsmouth; and Siobhan Thomas, London South Bank University.

\section{REFERENCES}

[1] Bayliss, J. D. and Bierre, K. 2008. Game design and development students: who are they? In Proceedings of the 3 rd international conference on Game development in computer science education (GDCSE '08). ACM, New York, NY, USA, 6-10. DOI=10.1145/1463673.1463675

[2] Braithwaite, B. and Schreiber, I. 2011. Breaking into the game industry. Course Technology PTR. Boston, MA, USA.

[3] Craig, M. and Horton, D. 2009. Gr8 Designs for Gr8 Girls: A Middle-School Program and its Evaluation. In SIGCSE 2009: The $40^{\text {th }}$ ACM Technical Symposium on Computer Science Education, Chattanooga, TN.

[4] Dietz, T. L. 1998. An examination of violence and gender role portrayals in video games: Implications for gender socialization and aggressive behavior. Sex Roles, 38, 425442.

[5] Dill, K. and Thill, K. 2007. Video game characters and the socialization of gender roles: Young people's perceptions mirror sexist media depictions. Sex Roles. 57:851-864.

[6] Downs, Edward, and Stacy L. Smith. "Keeping abreast of hypersexuality: A video game character content analysis." Sex Roles 62, no. 11 (2010): 721-733.

[7] Entertainment Software Association. (2012). Video Game Courses and Degree Programs Hit All-Time High at U.S. Colleges in All 50 States. Retrieved October 19, 2012 from http://www.theesa.com/newsroom/release_detail.asp?releaseI $\mathrm{D}=179$

[8] Everett, A. and Watkins, C. 2007. The power of play: The portrayal and performance of race in video games. The John D. and Catherine T. MacArthur Foundation Series on Digital Media and Learning (2007): 141-164.

[9] Glaubke, C., Miller, P., Parker, M., Espejo, E. (2001). Fair Play? Violence, gender and race in video games. Report from ChildrenNow. Retrieved December 7, 2012 from http://www.childrennow.org/index.php/learn/reports_and_res earch/article/219

[10] Graft, K. December 2012. The 5 trends that defined the game industry in 2012. Gamustra. Retrieved December 7, 2012 from http://www.gamasutra.com/view/news/182954/The_5 trends that_defined_the_game_industry_in_2012.php\#.UMIYYneO e_5g

[11] Higher Education Research Institute. 2012. CIRP Freshman Survey. Retrieved December 2012 from http://www.heri.ucla.edu/cirpoverview.php

[12] IGDA International Game Developers Association. 2005. Game Developer Demographics: An Exploration of Workforce Diversity. Retrieved October 15, 2011 from http:// www.igda.org/game-developer-demographics-report

[13] IGDA International Game Developers Association. 2011. Game Industry Survey 2011. Retrieved December, 2011 from http://www.research.net/s/IGDA_Industry_Survey_M2Resea rch

[14] Jansz, J, and Martis, R.G. 2007. The Lara phenomenon: Powerful female characters in video games. Sex Roles 56, no. 3 (2007): 141-148.

[15] Leonard, D. 2003. "Live in Your World, Play in Ours": Race, Video Games, and Consuming the Other." SIMILE: Studies in Media and Information Literacy Education 3(4), pp. 1-9.

[16] Martins, N, Williams, D.C., Harrison, K., Ratan, R.A. 2009. A content analysis of female body imagery in video games. Sex roles 61(11), pp. 824-836.

[17] Media Education Foundation. 2000. Game Over: Gender, Race, and Violence in Video Games. Available at http://www.mediaed.org/cgibin/commerce.cgi?preadd=action $\&$ key $=205$

[18] Packwood, D. 2011. Hispanics and Blacks Missing in Gaming Industry. News America Media. Retrieved December 7, 2012 from http://newamericamedia.org/2011/09/gamer-to-gamemakers-wheres-the-diversity.php

[19] Schott, G. and Horrell, K. 2000. Girl Gamers and their relationship with the gaming culture. Convergence, 6(4), 3654. Retreived on December 7, 2011 from http://con.sagepub.com/content/6/4/36.full.pdf

[20] Whitehead, J. 2008. Introduction to game design in the large classroom. In Proceedings of the 3rd international conference on Game development in computer science education (GDCSE '08). ACM, New York, NY, USA, 61-65. DOI $=10.1145 / 1463673.1463686$

[21] Williams, D., Martins, N., Consalvo, M., and Ivory, J. 2009. The virtual census: representations of gender, race and age in video games. New Media \& Society, 11:815. Retrieved December 7, 2012 from http://nms.sagepub.com/content/11/5/815.full.pdf + html 